\title{
MANEJO DA ÁGUA E DO NITROGÊNIO EM CULTIVO DE CAPIM-ELEFANTE ${ }^{1}$
}

\author{
Water and nitrogen management in the cultivation of elephant grass
}

\author{
Rodinei Facco Pegoraro ${ }^{2}$, Claudio Mistura ${ }^{3}$, Beno Wendling 4 , \\ Dilermando Miranda da Fonseca ${ }^{5}$, Jaílson Lara Fagundes ${ }^{6}$
}

\begin{abstract}
RESUMO
A intensificação do manejo do solo, visando ao aumento da produtividade de forrageiras pode contribuir para a degradação física e química do solo se mal conduzida. Neste contexto, o presente estudo objetivou avaliar a produção de MS, os conteúdos acumulados dos nutrientes na parte aérea de capim-elefante (Pennisetum purpureum Schum.) e as alterações nos atributos físicos e químicos do solo após a adição de doses de nitrogênio e aplicação ou não da irrigação. Para tanto, amostras de planta e solo foram coletadas em área experimental de pastagem com capim-elefante no quarto ano de cultivo sob doses crescentes de nitrogênio (100; 200; 300 e $400 \mathrm{~kg} \mathrm{ha}^{-1}$ de N, anualmente no período de verão) em sistema irrigado e não irrigado. Os resultados mostraram que após quatro anos de cultivo de capim-elefante o manejo com sistema irrigado combinado com adubação nitrogenada propiciou maior produção de MS da parte aérea, o que determinou maiores extrações de K, Ca e P pela planta, redução no teor de P extraível por Mehlich 1 no solo e incrementos nos teores de carbono orgânico total, $\mathrm{K}$ e Ca trocáveis. O solo com sistema não irrigado apresentou maior densidade.
\end{abstract}

Termos para indexação: Produção, extração de nutrientes, atributos do solo, Pennisetum purpureum.

\section{ABSTRACT}

The aim of this experiment was to evaluate the dry matter production and the content of nutrients accumulated in the aerial part of the elephant grass (Pennisetum purpureum Schum.) and alterations in the density and fertility of the soil after four years of fertilization with increasing nitrogen doses in an irrigated or non-irrigated cultivation area. For this purpose, plant and soil samples were collected from an experimental area of pasture with elephant grass in the fourth year of cultivation under increasing doses of nitrogen $\left(100,200,300\right.$, and $400 \mathrm{~kg} \mathrm{ha}^{-1} \mathrm{~N}$, yearly in the summer) in both systems. The results showed that after four years of elephant grass cultivation, the irrigated system combined with nitrogen fertilization presented larger production of dry matter of the aerial part, which determined larger contents of the mineral elements $\mathrm{K}, \mathrm{Ca}$, and $\mathrm{P}$ in the plant. Also higher reduction in the content of $\mathrm{P}$ and increase of total organic $\mathrm{C}, \mathrm{K}$ and $\mathrm{Ca}$ were observed in the irrigated soil in comparison to the non-irrigated system. The density was larger in the non-irrigated system.

Index terms: Pasture yield, nutrient extraction, attributes of the soil, Pennisetum purpureum.

(Recebido em 10 de janeiro de 2007 e aprovado em 4 de outubro de 2007)

\section{INTRODUÇÃOO}

A produção de forragem, como resultado dos processos de crescimento e desenvolvimento, pode ter sua eficiência substancialmente melhorada pelo uso adequado de fertilizantes, principalmente o nitrogênio $(\mathrm{N})$ que promove, juntamente com o uso adequado da água de irrigação, expressivo aumento na produção e qualidade de forragens (DURU \& DUCROCQ, 2000; MISTURA, 2004), especialmente em épocas menos chuvosas do ano nas regiões tropicais. Contudo, mudanças no manejo do solo de pastagens podem causar alterações em alguns de seus atributos químicos e físicos, como aumento da compactação e redução no teor de nutrientes, em virtude da maior absorção pelas plantas, impactando negativamente na qualidade do solo ao longo dos anos de cultivo.

A maior produção de forragens nas áreas de cultivo intensivo possibilita o aumento da taxa de lotação animal que pode chegar até $10 \mathrm{UA} \mathrm{ha}^{-1}$, com ganhos de peso vivo

\footnotetext{
${ }^{1}$ Projeto financiado parcialmente pela CAPES e CNPq

${ }^{2}$ Engenheiro Agrônomo, Doutor em Solos e Nutrição de Plantas, Professor - Departamento de Ciências Agrárias - Universidade Estadual de Montes Claros/UNIMONTES - Avenida Reinaldo Viana, 2630 - Bico da Pedra - Cx. P. 91 - 39440-000 - Janaúba, MG - rodinei_pegoraro@yahoo.com.br ${ }^{3}$ Engenheiro Agrônomo, Doutor em Zootecnia, Professor - Departamento de Tecnologia e Ciências Sociais/DTCS - Universidade do Estado da Bahia/ UNEB - Campus III - Avenida Edghard Chastinet, s/n - São Geraldo - 48905-680 - Juazeiro, BA - cmistura@ig.com.br ${ }^{4}$ Engenheiro Agrônomo, Doutor em Solos e Nutrição de Plantas - Departamento de Solos - Universidade Federal de Viçosa/UFV - Avenida P.H. Rolfs, $\mathrm{s} / \mathrm{n}$ - 36571-000 - Viçosa, MG - benowendling@yahoo.com.br ${ }^{5}$ Zootecnia, Ph.D., Professor - Departamento de Zootecnia - Universidade Federal de Viçosa/UFV - Avenida P.H. Rolfs, s/n - 36571-000 - Viçosa, MG dfonseca@ufv.br

${ }^{6}$ Engenheiro Agrônomo, Doutor em Zootecnia - Departamento de Zootecnia - Universidade Federal de Viçosa/UFV - Avenida P.H. Rolfs, s/n - 36571000 - Viçosa, MG - ratinhojlf@yahoo.com.br
} 
na faixa de $1,0 \mathrm{~kg} \mathrm{dia}{ }^{-1}$ (ANDRADE, 2000). A maior intensificação do contato do casco animal com o solo pode favorecer a sua compactação, principalmente em áreas ocupadas por forrageiras cespitosas (capim-elefante, por exemplo), pois limita o tráfego animal nas entrelinhas de cultivo e contribui para a degradação física do solo (COSTA et al., 1996). Por sua vez, uma maior produção de massa vegetal aumenta a deposição de resíduos na superfície e pode incrementar o teor de matéria orgânica do solo ao longo dos anos de cultivo.

A compactação do solo de pastagens cultivadas é generalizada, geralmente em conseqüência do manejo inadequado. Os processos de degradação física, como a compactação, aumentam a densidade do solo; a resistência à penetração das raízes; diminuem a infiltração de água, pela redução de macroporos, e resultam em aumento da possibilidade de ocorrência de enxurradas (HILLEL, 1982), gerando problemas nutricionais às plantas em razão da diminuição da disponibilidade de nutrientes (CAMARGO \&ALLEONI, 1997)

Neste trabalho, objetivou-se avaliar o efeito de quatro anos de fertilização com doses crescentes de $\mathrm{N}$ em sistemas de cultivo irrigado ou não irrigado com pastejo animal na produção de MS, na extração dos nutrientes $\mathrm{N}$, $\mathrm{P}, \mathrm{K}, \mathrm{Ca}$ e $\mathrm{Mg}$ na parte aérea e as possíveis alterações na densidade e em atributos químicos do solo (pH e os teores de carbono orgânico, $\mathrm{Ca}, \mathrm{Mg}, \mathrm{K}$ e $\mathrm{P}$ do solo) cultivado com capim-elefante (Pennisetum purpureum Schum.).

\section{MATERIAL E MÉTODOS}

O experimento foi conduzido na Universidade Federal de Viçosa (UFV), em Viçosa, MG, no setor de Agrostologia do Departamento de Zootecnia, durante o período de novembro de 1998 a outubro de 2002. A temperatura média anual de Viçosa é de $19^{\circ} \mathrm{C}$. A umidade relativa média do ar foi de $80 \%$ e a precipitação média anual de $1.341 \mathrm{~mm}$, com estações seca e chuvosa bem definidas.

O experimento consistiu de um fatorial $2 \times 4$, em que se comparou o sistema de irrigação (irrigado ou não) e quatro doses de $\mathrm{N}\left(100,200,300\right.$ e $\left.400 \mathrm{~kg} \mathrm{ha}^{-1} \mathrm{ano}^{-1}\right)$. Para a realização destas comparações foram amostradas três profundidades distintas $(0-5 ; 5-10$ e $10-20 \mathrm{~cm})$ no perfil do solo, sendo distribuídas em blocos ao acaso com três repetições.

O experimento foi instalado no período de outubro de 2001 a outubro de 2002 em área de capim-elefante consolidado, ou seja, área cultivada há três anos em um Latossolo amarelo. Esse cultivo recebia pastoreio animal intermitente, conforme a disponibilidade temporal de forragem. A área experimental correspondeu a $7.200 \mathrm{~m}^{2} \mathrm{e}$ foi dividida em duas partes, sendo a metade $\left(3.600 \mathrm{~m}^{2}\right)$ irrigada e a outra $\left(3.600 \mathrm{~m}^{2}\right)$ não irrigada. A unidade experimental consistiu de parcela (piquete) de $300 \mathrm{~m}^{2}(17,32$ $\mathrm{x} 17,32 \mathrm{~m}$ ), perfazendo um total de 24 piquetes nas duas áreas, irrigada e sequeiro.

Inicialmente, foi realizada a análise do solo para correção do $\mathrm{pH}$ e dos teores de nutrientes para cultivo do capim-elefante (CANTARUTTI et al., 1999). Além da correção do solo, toda a área experimental recebeu adubação de manutenção correspondente a $50 \mathrm{~kg} \mathrm{ha}^{-1} \mathrm{de}$ $\mathrm{P}_{2} \mathrm{O}_{5}$ (superfosfato simples) e $200 \mathrm{~kg} \mathrm{ha}^{-1}$ de $\mathrm{K}_{2} \mathrm{O}$ (cloreto de potássio) em todos os piquetes, aplicados a lanço na superfície do solo, numa única dose no início da estação chuvosa.

As doses de $\mathrm{N}$, na forma de uréia, foram aplicadas em épocas distintas para cada sistema de irrigação. $\mathrm{Na}$ área irrigada, do total de $100 \%$ das doses dos tratamentos, $70 \%$ foram aplicados no período das águas, distribuídos no início, meio e fim (novembro, dezembro e fevereiro) e os $30 \%$ restantes, no início do período seco (abril), em dose única. Já na área não irrigada, aplicaram-se os $100 \%$ dos tratamentos de $\mathrm{N}$ no período das águas, utilizando o mesmo critério adotado na área irrigada.

No período experimental houve cinco ciclos de pastejo sob lotação rotativa com três vacas da raça girolando (vacas secas) por piquete $\left(300 \mathrm{~m}^{2}\right)$ em um período de dois dias $( \pm 1)$, conforme a massa de forragem na pastagem, retornando quando as plantas atingissem uma altura média de 1,70 m acima do solo. Durante o experimento foi efetuada a avaliação do índice de cobertura vegetal do solo (IC). Para estimativa do IC, alocaram-se aleatoriamente três áreas de 4 $\mathrm{m}^{2}$ dentro de cada piquete. Após a alocação de cada área, dois avaliadores estimaram, independentemente, o percentual da área coberta por touceiras e, ou, plantas de capim-elefante, numa escala de 0 a $100 \%$.

A irrigação foi realizada por meio de um sistema de aspersão convencional de média pressão, manejada com turno de rega variável, usando-se o método do tanque "Classe A" para a estimativa da evapotranspiração de referência. A irrigação foi efetuada sempre que o valor do somatório da evapotranspiração real da cultura, subtraído da precipitação efetiva, fosse aproximadamente igual a 50\% do valor da capacidade real de água no solo (CRA), tanto para o período das águas como para o seco.

Ao final do período experimental, coletaram-se amostras de planta (folhas e colmos) e solo na camada de $0-20 \mathrm{~cm}$, em três profundidades $(0-5 ; 5-10$ e 10-20 cm). As amostras de planta foram secas em estufa por um período de $48 \mathrm{~h}$ a $65^{\circ} \mathrm{C}$ e pesadas para determinação da MS total produzida. Em seguida, as amostras foram trituradas e homogeneizadas para determinação dos teores de N, P, K, $\mathrm{Ca}$ e $\mathrm{Mg}$, com o intuito de quantificar a extração total 
realizada pelas plantas, conforme o método descrito por Silva \& Queiroz (2002).

A coleta das amostras de solo, em cada camada, seguiu o método do anel volumétrico (EMBRAPA, 1997), amostrando-se três pontos simples que deram origem a uma amostra composta por repetição. Inicialmente, determinouse a densidade do solo utilizando as amostras indeformadas da coleta; posteriormente, estas foram secas ao ar (TFSA), trituradas e homogeneizadas. Diferentes alíquotas de solo foram retiradas para determinação do $\mathrm{pH}$ em água e teores de $\mathrm{N}$ (Kjeldahl), P, K (Mehlich 1), Ca e Mg (KCl $1 \mathrm{~mol} \mathrm{~L}^{-1}$ ), conforme Embrapa (1997), e carbono orgânico total do solo (YEOMANS \& BREMNER, 1988). Também, estimaram-se os teores relativos desses nutrientes para cada camada de solo em relação ao somatório das três camadas:

$$
T(\%)=\frac{\text { Camada }}{\sum \text { camadas }} x 100
$$

Onde: $T(\%)$ : é o teor relativo do nutriente, em percentagem; Camada: é o teor do nutriente em cada camada (0-5, 5-10 e $10-20 \mathrm{~cm})$ e $\sum$ camadas : é o somatório do teor do nutriente nas três camadas $(0-20 \mathrm{~cm})$ do solo.

Os resultados foram submetidos à análise de variância para modelos fatoriais, testando-se as interações entre sistema $\mathrm{x}$ dose de $\mathrm{N}$ para cada camada amostrada (05, 5-10 e 10-20 cm), pelo programa SAEG 5.0. Efetuou-se o estudo de regressão polinomial para as doses de $\mathrm{N}$ e o teste de comparação entre médias (Tukey, $\mathrm{P} \leq 0,05)$ para a comparação entre os sistemas de irrigação.

\section{RESULTADOS E DISCUSSÃO}

Os resultados obtidos demonstraram a existência de interação significativa $(\mathrm{P} \leq 0,05)$ entre sistema de irrigação x doses de $\mathrm{N}$ para produção de MS e conteúdos de N, P, K, Ca e Mg na parte aérea do capim-elefante. O aumento das doses de $\mathrm{N}$ propiciou incrementos lineares em todas estas variáveis, tanto na área irrigada quanto na não irrigada (Figura 1). A produção de MS na área irrigada superou a da não irrigada por cerca de $15 \%\left(8,45 \mathrm{tha}^{-1}\right)$ na maior dose de $\mathrm{N}$ aplicada (400 $\mathrm{kg} \mathrm{ha}^{-1}$ ), aumentando a disponibilidade de forragem para o pastejo dos animais.

As produções de forragem do capim-elefante foram incrementadas em $85 \%\left(26,07 \mathrm{tha}^{-1}\right)$ e $77 \%\left(28,45 \mathrm{t} \mathrm{ha}^{-1}\right)$ na maior dose de $\mathrm{N}$ (400 $\mathrm{kg} \mathrm{ha}^{-1}$ ), comparadas ao tratamento que recebeu $100 \mathrm{~kg} \mathrm{ha}^{-1}$ de $\mathrm{N}$, para os sistemas não irrigado e irrigado, respectivamente. Dessa forma, verificou-se maior eficiência da adubação nitrogenada no sistema não irrigado, embora a maior produção de MS tenha sido quantificada no sistema irrigado.
Os efeitos de irrigação e adubação em 10 gramíneas no período seco, em duas regiões do Estado de Minas Gerais, foram estudados por Pereira et al. (1966). Os autores observaram que a adubação nitrogenada sem a irrigação aumentou a produção de forragem verde das gramíneas em 56\% numa localidade, enquanto na outra não houve diferença entre os tratamentos. Em ambos os locais, as produções de forragem aumentaram em 62 e $72 \%$, como consequiência da irrigação sem adubação. A interação entre a irrigação e adubação aumentou a produção de forragem em 209 e $176 \%$, em cada uma das regiões.

No entanto, Andrade (1972), estudando o efeito da irrigação na produção de capim-elefante no Triângulo Mineiro, obteve ganhos de produção com a irrigação de apenas $25 \%$, alegando que este incremento não foi suficiente para corrigir a estacionalidade da produção forrageira na seca, atribuindo à temperatura a provável causa da baixa produtividade. Jacques (1994) afirma que o melhor desenvolvimento do capimelefante é obtido com precipitações de 800 a $4000 \mathrm{~mm}$ e temperaturas próximas de $24^{\circ} \mathrm{C}$.

Além da irrigação, sem dúvida, o $\mathrm{N}$ é um dos macronutrientes que apresenta maior influência sobre a produtividade e qualidade da forragem, desde que os demais nutrientes estejam em equilíbrio na solução do solo, ou seja, não estejam limitando o desenvolvimento das plantas. Estudos mais recentes com o N têm demonstrado o seu efeito positivo sobre as características morfogênicas e estruturais das plantas forrageiras (DURU \& DUCROCQ, 2000; GARCEZ NETO et al., 2002; LOPES et al., 2003, 2005).

Os conteúdos dos elementos minerais $\mathrm{N}, \mathrm{P}, \mathrm{K}, \mathrm{Ca}$ e $\mathrm{Mg}$ apresentaram aumentos lineares com o incremento da adubação nitrogenada, sendo que no sistema irrigado os conteúdos de $\mathrm{K}, \mathrm{P}$ e Ca foram maiores em decorrência da maior produção de MS obtida. Para o N e o Mg não houve diferença entre os sistemas (Figura 1).

$\mathrm{O} \mathrm{K}$ foi o nutriente que apresentou maior conteúdo médio dos dois sistemas, exportado do solo pela planta $( \pm$ $\left.1.700 \mathrm{~kg} \mathrm{ha}^{-1}\right)$, seguido do $\mathrm{N}\left( \pm 900 \mathrm{~kg} \mathrm{ha}^{-1}\right)$, do Ca $( \pm 300 \mathrm{~kg}$ ha $\left.^{-1}\right)$, do $\mathrm{P}\left( \pm 150 \mathrm{~kg} \mathrm{ha}^{-1}\right)$ e, por último, do $\mathrm{Mg}\left( \pm 100 \mathrm{~kg} \mathrm{ha}^{-1}\right)$, na maior dose de $\mathrm{N}$. Isto demonstra a alta capacidade de extração de nutrientes pela planta forrageira no período de um ano de cultivo, sendo extremamente necessária a reposição via fertilizantes destes nutrientes ao solo. Carvalho et al. (1991) obtiveram extrações de $\mathrm{N}$ entre $66 \mathrm{e}$ $317 \mathrm{~kg} \mathrm{ha}^{-1} \mathrm{ano}^{-1}$ e de K entre 53 e $188 \mathrm{~kg} \mathrm{ha}^{-1}$ ano $^{-1}$ após a aplicação de doses de $\mathrm{N}$ e $\mathrm{K}$ ao solo em pastagem em Brachiaria decumbens Stapf num Latossolo Vermelho Amarelo de Minas Gerais. Tais extrações foram bem inferiores às obtidas neste estudo com pastagem de capimelefante, mostrando que esta forrageira requer sistemas 

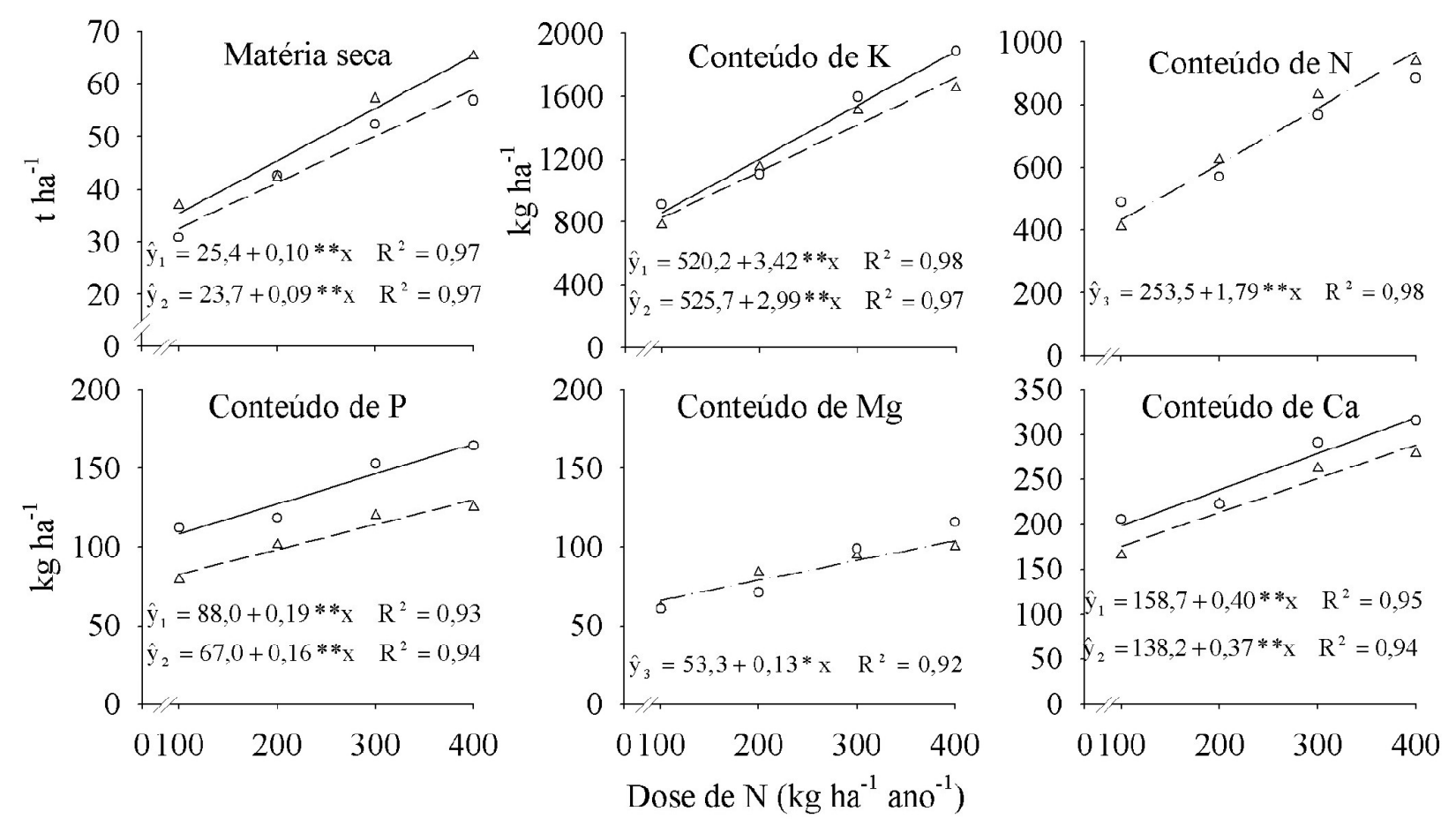

Figura 1 - Produção de matéria seca e conteúdos de N, P, K, Ca e Mg no capim-elefante após adição das doses de N. 1. irrigado $(-) ; 2$. não irrigado $(--) ; 3$. irrigado mais não irrigado $(-\cdot-)$, quando não houve diferença significativa entre os sistemas $(\mathrm{P}>0,05)$.

mais intensivos de correção nutricional e hídrica para o melhor aproveitamento de seu potencial de produção.

Para a maioria dos atributos químicos e físicos do solo, a interação entre sistemas de irrigação $\mathrm{x}$ doses de $\mathrm{N}$ não foi significativa $(\mathrm{P}>0,05)$ nas três camadas de solo amostradas (0-5; 5-10 e 10-20 cm), assim como para as doses de $\mathrm{N}$ testadas isoladamente. Somente o carbono orgânico total (COT), na camada de $0-5 \mathrm{~cm}$, e a densidade do solo, na camada de $5-10 \mathrm{~cm}$, foram influenciados pela adição de N. Ajustando-se uma equação quadrática $\left(\hat{y}=2,9-0,005 * \mathrm{x}+0,00001 * x^{2} ; \quad R^{2}=0,99\right)$, o teor de COT no solo decresceu com a adição de doses intermediárias de $\mathrm{N}$ ( 200 e $300 \mathrm{~kg} \mathrm{ha}^{-1}$ ) e aumentou com a maior dose $\left(400 \mathrm{~kg} \mathrm{ha}^{-1}\right)$. Já, para a densidade do solo, obteve-se decréscimo linear com o aumento das doses de $\mathrm{N}\left(\hat{y}=1,3-0,0002 * * \mathrm{x} ; \quad R^{2}=0,54\right)$.

$\mathrm{O}$ aumento da produção da forrageira associado aos processos de humificação da matéria orgânica do solo pode ter propiciado a ocorrência de tal fenômeno para o COT na camada superficial $(0-5 \mathrm{~cm})$. $\mathrm{O}$ incremento do $\mathrm{N}$ no solo pode causar redução da habilidade competitiva de fungos que são responsáveis pela decomposição da lignina (FOG, 1988), suprimindo a formação de enzimas que fazem sua quebra (CARREIRO et al., 2000) e reagir com resíduos de lignina (e outros compostos fenólicos) mais abundantes nos resíduos de forragem deste tratamento (justificado pela maior produção de colmos, tecido de sustentação mais lignificado) (MISTURA, 2004), formando complexos de alta resistência à degradação microbiana (STEVENSON, 1994), o que favoreceria o aumento do teor de COT na maior dose de $\mathrm{N}$ aplicada ao solo.

Ao comparar os solos submetidos aos dois sistemas de irrigação, obteve-se, na camada de $0-20 \mathrm{~cm}$, valores médios menores para densidade do solo e teor de $\mathrm{P}$ e maiores teores de COT, $\mathrm{K}$ e Ca no sistema irrigado (Tabela 1). Para o teor médio de Mg não se obteve diferença significativa $(\mathrm{P}>0,05)$ entre os sistemas de irrigação. Essas diferenças foram evidenciadas nas camadas superficiais $(0-5$ e $5-10 \mathrm{~cm})$ do solo para COT e P; nas camadas inferiores, para K e Ca (5-10 e 10-20 cm), e nas três camadas de solo, para densidade (Tabela 1). Infere-se que as diferenças encontradas entre os sistemas de irrigação estão associadas à maior deposição de resíduos vegetais ao solo, demonstrado pelo maior índice de cobertura do solo (irrigado, $\hat{\mathrm{y}}_{1}=36,24+0,018 * \mathrm{x} ; \quad \mathrm{R}^{2}=0,91$ e não irrigado, $\left.\hat{\mathrm{y}}_{2}=24,03+0,014 * x ; \quad \mathrm{R}^{2}=0,91\right)$, o que também pode ser extrapolado ao volume do sistema radicular presente na subsuperfície do solo. 
Tabela 1 - Valores médios e relativos (entre parênteses, em \%) de densidade e carbono orgânico total $(\mathrm{COT}), \mathrm{pH}_{(\mathrm{H} 2 \mathrm{O})}, \mathrm{P}$, $\mathrm{K}, \mathrm{Ca}$ e Mg nas camadas (0-5; 5-10 e 10-20 cm) de solo, após quatro anos de cultivo de capim-elefante nos sistemas não irrigado e irrigado.

\begin{tabular}{ccccccccc}
\hline Sistemas & Prof.* & Densidade & COT & $\mathrm{pH}$ & $\mathrm{P}$ & $\mathrm{K}$ & $\mathrm{Ca}$ & $\mathrm{Mg}$ \\
\hline & & $\mathrm{g} \mathrm{cm}^{-3}$ & $\mathrm{dag} \mathrm{kg}^{-1}$ & & $\mathrm{mg} \mathrm{dm}^{-3}$ & $\mathrm{mg} \mathrm{dm}^{-3}$ & $\mathrm{cmol}_{\mathrm{c}} \mathrm{dm}^{-3}$ & $\mathrm{cmol}_{\mathrm{c}} \mathrm{dm}^{-3}$ \\
Não & $0-5$ & $1,42 \mathrm{a}$ & $2,17 \mathrm{~b}(41)$ & $6,14 \mathrm{a}$ & $5,37 \mathrm{a}(58)$ & $151,67 \mathrm{a}(58)$ & $3,05 \mathrm{a}(41)$ & $1,30 \mathrm{a}(45)$ \\
irrigado & $5-10$ & $1,35 \mathrm{a}$ & $1,70 \mathrm{~b}(32)$ & $6,01 \mathrm{a}$ & $2,75 \mathrm{a}(30)$ & $72,83 \mathrm{~b}(27)$ & $2,55 \mathrm{a}(34)$ & $0,95 \mathrm{a}(33)$ \\
& $10-20$ & $1,33 \mathrm{a}$ & $1,44 \mathrm{a}(27)$ & $5,85 \mathrm{~b}$ & $1,19 \mathrm{a}(12)$ & $41,00 \mathrm{~b}(15)$ & $1,93 \mathrm{~b}(25)$ & $0,66 \mathrm{a}(22)$ \\
& Média $^{¥}$ & $1,37 \mathrm{~A}$ & $1,77 \mathrm{~B}$ & $6,00 \mathrm{~A}$ & $3,10 \mathrm{~A}$ & $88,50 \mathrm{~B}$ & $2,51 \mathrm{~B}$ & $0,97 \mathrm{~A}$ \\
& $0-5$ & $1,26 \mathrm{~b}$ & $2,48 \mathrm{a}(43)$ & $5,92 \mathrm{a}$ & $3,52 \mathrm{~b}(50)$ & $179,33 \mathrm{a}(52)$ & $3,12 \mathrm{a}(38)$ & $1,19 \mathrm{a}(41)$ \\
Irrigado & $5-10$ & $1,24 \mathrm{~b}$ & $1,91 \mathrm{a}(32)$ & $6,14 \mathrm{a}$ & $2,40 \mathrm{a}(34)$ & $108,83 \mathrm{a}(32)$ & $2,78 \mathrm{a}(33)$ & $0,92 \mathrm{a}(32)$ \\
& $10-20$ & $1,25 \mathrm{~b}$ & $1,50 \mathrm{a}(25)$ & $6,14 \mathrm{a}$ & $1,17 \mathrm{a}(16)$ & $56,00 \mathrm{a}(16)$ & $2,41 \mathrm{a}(29)$ & $0,79 \mathrm{a}(27)$ \\
& Média $^{¥}$ & $1,25 \mathrm{~B}$ & $1,97 \mathrm{~A}$ & $6,07 \mathrm{~A}$ & $2,36 \mathrm{~B}$ & $114,72 \mathrm{~A}$ & $2,77 \mathrm{~A}$ & $0,97 \mathrm{~A}$ \\
\hline
\end{tabular}

* - Médias seguidas pela mesma letra minúscula em cada profundidade e letras maiúsculas nas médias, na coluna, não diferem entre si pelo teste de Tukey $(\mathrm{P}>0,05){ }^{¥}{ }^{*}$ - média de três profundidades $(0-5 ; 5-10$ e $10-20 \mathrm{~cm})$.

A maior compactação observada nas três camadas de solo no sistema não irrigado (Tabela 1) pode ser justificada pela característica da espécie forrageira associada à intensificação do ciclo de umedecimento e secagem e do pisoteio animal (pela menor cobertura vegetal do solo, propiciando maior contato da pata do animal com o solo), ou seja, o capim-elefante não possui boa cobertura do solo pelas touceiras, por apresentar o hábito de crescimento cespitoso e ser de porte alto.

Numa condição de menor desenvolvimento vegetativo (período seco do ano), pode ocorrer maior exposição do solo (menor cobertura vegetal e volume de raízes) às condições de clima e manejo. Sem a proteção orgânica, os ciclos de umedecimento e secagem se intensificam, possibilitando a elevação do grau de compactação do solo, assim como para o pisoteio animal. Demonstrativamente, o índice de cobertura do solo (IC) foi acrescido com o aumento das doses de $\mathrm{N}$, porém inferior no sistema não irrigado, como foi discutido nos parágrafos anteriores. Exemplo típico, que pode ser citado como comparativo para estes resultados, é o do capim-colonião que, por apresentar hábito de crescimento ereto, não cobre bem o solo entre as touceiras como as espécies decumbentes (Brachiaria ssp.), o que determina uma maior susceptibilidade ao impacto da gota da chuva e ao pisoteio animal, aumentando a degradação física do solo (RESENDE et al., 1993).

A partir de $5 \mathrm{~cm}$ de profundidade, obteve-se redução na densidade do solo, o que reforça as considerações citadas anteriormente, pois o aumento da densidade causada pelos animais em pastejo não se reflete significativamente nas camadas mais profundas, ao contrário do que ocorre com uso de máquinas agrícolas pesadas (KONDO \& DIAS JUNIOR, 1999).
Os teores relativos de COT, $\mathrm{P}, \mathrm{K}, \mathrm{Ca}$ e $\mathrm{Mg}$, descritos entre parênteses na Tabela 1 , foram reduzidos com $\mathrm{O}$ aumento da profundidade do solo. Esse comportamento é observado na maioria das culturas onde o solo não é revolvido constantemente. Tal fator pode estar associado ao processo de ciclagem de nutrientes na superfície do solo, uma vez que grande parte da MS que foi produzida pela forrageira acaba sendo acumulada sobre o solo no momento do pastoreio.

Apesar do estoque de nutrientes ter aumentado linearmente na planta com o aumento das doses de $\mathrm{N}$ no solo, não se constatou, necessariamente, reduções nos teores de nutrientes no solo, somente registrando-se diferenças entre os sistemas de irrigação (Tabela 1). A maior capacidade de exportação de P (aproximadamente 29\%, $30,5 \mathrm{~kg} \mathrm{ha}^{-1}$ ano $^{-1}$ a mais) pelo capim-elefante, no sistema irrigado, ocasionou redução do seu teor na camada média de $0-20 \mathrm{~cm}$, puxada pelo menor teor de $\mathrm{P}$ obtido na superfície do solo $(0-5 \mathrm{~cm})$. Isto demonstra a existência de exaustão do nutriente no solo, o que poderá limitar a produção da planta em ciclos subseqüentes.

Com a adição de fertilizantes nitrogenados ao solo é natural que o $\mathrm{pH}$ em $\mathrm{H}_{2} \mathrm{O}$ decresça. Este fato não foi observado no presente estudo, possivelmente porque a matéria orgânica do solo tenha suprimido o efeito acidificante da adubação nitrogenada com o tempo de cultivo da forrageira. Sá (1999), após aplicar N por vários anos em solos cultivados com milho no estado do Paraná, cultura esta muito exigente em adubação nitrogenada, verificou tendência de redução do $\mathrm{pH}$ ao longo dos anos. Essa ação acidificante foi minimizada em solos com alto teor de carbono orgânico em sistemas que privilegiem o aumento de resíduos vegetais ao solo, como o sistema de 
semeadura direta (FRANCHINI et al., 2000; HOLANDA et al., 1998).

\section{CONCLUSÕES}

A biomassa da parte aérea e os conteúdos de N, P, $\mathrm{K}$, Ca e Mg aumentam linearmente com o incremento das doses de $\mathrm{N}$ adicionadas à pastagem de capim-elefante. $\mathrm{Na}$ área irrigada, constatam-se maiores produções de MS e extrações de $\mathrm{Ca}$, $\mathrm{K}$ e $\mathrm{P}$ e iguais de $\mathrm{N}$ e $\mathrm{Mg}$, em comparação à área não irrigada. As doses de $\mathrm{N}$ não influenciam a maioria dos atributos químicos e físicos do solo; já a irrigação aumenta os teores de COT, $\mathrm{K}$ e Ca, reduz o teor de $\mathrm{P}$ e mantém os mesmos teores de $\mathrm{Mg}$ e valores de $\mathrm{pH}$ do sistema não irrigado

\section{REFERÊNCIAS BIBLIOGRÁFICAS}

ANDRADE, C. M. S. Produção de bovinos em pastagem irrigada. Disponível em: <Lww.forragicultura.com.bri arquivos/irrigaçãopastagem?. Viçosa: UFV, 2000. Acesso em: 26 mar. 2003.

ANDRADE, J. M. S. Efeito das adubações química e orgânica e da irrigação sobre a produção e o valor nutritivo do capim-elefante "Mineiro" em latossolo roxo distrófico do município de Ituiutaba, MG. 1972. 42 f. Dissertação (Mestrado) - Universidade Federal de Viçosa, Viçosa, 1972.

CAMARGO, O. A.; ALLEONI, L. R. E. Compactação do solo e desenvolvimento das plantas. Piraciacaba: Degaspar, 1997. $132 \mathrm{p}$.

CANTARUTTI, R. B.; MARTINS, C. E.; CARVALHO, M. M.; FONSECA, D. M.; ARRUDA, M. L.; VILELA, H.; OLIVEIRA, F. T. T. Pastagens. In: RIBEIRO, A. C.; GUIMARÃES, P. T. G.; ALVAREZ, V. H. (Eds.).

Recomendação para o uso de corretivos e fertilizantes em Minas Gerais: $5^{\text {a }}$ aproximação. Viçosa: UFV, 1999. 359 p.

CARREIRO, M. M.; SINSABAUGH, R. L.; REPERT, D. A.; PARKHURST, D. F. Microbial enzyme shifts explain litter decay responses to simulated nitrogen deposition. Ecology, Washington, v. 81, n. 9, p. 2359-2365, 2000.

CARVALHO, M. M.; MARTINS, C. E.; VERNEQUE, R. S.; SIQUEIRA, C. Resposta de uma espécie de Braquiária à fertilização com nitrogênio e potássio em um solo ácido. Revista Brasileira de Ciência do Solo, Campinas, v. 15, p. 195-200, 1991.
COSTA, L. M.; JUCKSCH, I.; GJORUP, G. B. Fertilidade e manejo de solos. In: . Curso de especialização por tutoria à distância. Brasília, DF: ABEAS, 1996. 61 p.

DURU, M.; DUCROCQ, H. Growth and senescence of the successive leaves on a cocksfoot tiller. Effect of nitrogen and cutting regime. Annals of Botany, Castanet Tolosan, v. 85, n. 5, p. 645-653, 2000.

EMPRESA BRASILEIRA DE PESQUISA

AGROPECUÁRIA. Manual de métodos de análises de solo. 2. ed. Rio de Janeiro, 1997. 212 p.

FOG, K. The effect of added nitrogen on the rate of decomposition of organic matter. Biological Reviews, [S.1.], v. 63, n. 3, p. 433-462, 1988.

FRANCHINI, J. C.; BORKERT, C. M.; FERREIRA, M. M.; GAUDÊNCIO, C. A. Alterações na fertilidade do solo em sistemas de rotação de culturas em semeadura direta.

Revista Brasileira de Ciência do Solo, Viçosa, v. 24, n. 2, p. 459-467, 2000.

GARCEZ NETO, A. F.; NASCIMENTO JUNIOR, D.; REGAZZI, A. J.; FONSECA, D. M.; MOSQUIM, P. R.; GOBBI, K. F. Respostas morfogênicas e estruturais de Panicum maximum cv. Mombaça sob diferentes doses de adubação nitrogenada e alturas de corte. Revista Brasileira de Zootecnia, Viçosa, v. 31, n. 5, p. 1890-1900, 2002.

HILLEL, D. Introduction to soil physics. San Diego: Academic, 1982. 264 p.

HOLANDA, F. S. R.; MENGEL, D. B.; PAULA, M. B.; CARVALHO, J. G.; BERTONI, J. C. Influence of crop rotation and tillage systems on phosphorus and potassium stratification and root distribution in the soil profile. Communications in soil science and plant analysis, New York, v. 29, n. 15/16, p. 2383-2394, 1998.

JACQUES, A. V. A. Características morfofisiológicas e suas implicações no manejo. In: Capimelefante, produção e utilização. Coronel Pacheco: Embrapa/CNPGL, 1994. p. 31-48.

KONDO, M. K.; DIAS JUNIOR, M. S. Efeito do manejo e da umidade no comportamento compressivo de três latossolos. Revista Brasileira de Ciência do Solo, Viçosa, v. 23, n. 3, p. 497-506, 1999. 
LOPES, R. S.; FONSECA, D. M.; OLIVEIRA, R. A.; ANDRADE, A. C.; NASCIMENTO JUNIOR, D.; MASCARENHAS, A. G. Efeito da irrigação e adubação na disponibilidade e composição bromatológica da massa seca de lâminas foliares de capim-elefante.

Revista Brasileira de Zootecnia, Viçosa, v. 34, n. 1, p. 20 29, 2005.

LOPES, R. S.; FONSECA, D. M.; OLIVEIRA, R. A.; NASCIMENTO JUNIOR, D.; ANDRADE, A. C.; STOCK, L. A.; MARTIN, C. E. Disponibilidade de matéria seca em pastagens de capim-elefante irrigadas. Ciência e Agrotecnologia, Lavras, v. 27, n. 6, p. 1388-1394, 2003.

MISTURA, C. Adubação nitrogenada e irrigação em pastagem de capim-elefante. 2004. $72 \mathrm{f}$. Tese (Doutorado em Zootecnia) - Universidade Federal de Viçosa, Viçosa, 2004.

PEREIRA, R. M. A.; SYKES, D. J.; GOMIDE, J. A.; VIDIGAL, G. T. Competição de dez gramíneas para capineira no cerrado, em 1965. Revista Ceres, Viçosa, v. 13, p. 141-153, 1966.
RESENDE, M.; LANI, J. L.; FEITOSA, L. R. Assentamento de pequenos agricultores no Estado do Espírito Santo: ambiente, homem e instituições. Vitória: EMCAPA, 1993. 152 p.

SÁ, J. C. M. Manejo da fertilidade do solo em sistema plantio direto. In: SIQUEIRA, J. O.; MOREIRA, F. M. S.; LOPES, A. S.; GUILHERME, L. R. G.; FAQUIN, V.; FURTINI NETO, A. E.; CARVALHO, J. G. (Eds.). Interrelação fertilidade, biologia do solo e nutrição do solo. Lavras: UFLA, 1999. p. 267-310.

SILVA, D. J.; QUEIROZ, A. C. Análise de alimentos: métodos químicos e biológicos. 3. ed. Viçosa: UFV, 2002. $235 \mathrm{p}$.

STEVENSON, F. J. Humus chemistry: genesis, composition and reactions. 2. ed. New York: Willey \& Sons, 1994. 496 p.

YEOMANS, J. C.; BREMNER, J. M. A rapid and precise method for routine determination of organic carbon in soil. Communications in soil science and plant analysis, New York, v. 19, n. 13, p. 1467-1476, 1988. 